Methods: We conducted a cross-sectional study comparing MN US parameters of SSc patients followed up at our Rheumatology Unit and control subjects. Exclusion criteria included body mass index $(\mathrm{BMI})>30$, previous wrist trauma and known diagnosis of carpal tunnel syndrome. Forty-eight out of $62 \mathrm{SSc}$ patients and 45 healthy age and sex matched controls were enrolled. Subjects were consecutively evaluated in our Department. A General Electric LOGIQ S8 US with a $15 \mathrm{MHz}$ linear transducer was used for assessment. MN cross-sectional area (MNA) and perimeter (MNP) of both sides of each person were measured at the level of the carpal tunnel inlet. For comparative analysis, the mean MNA and MNP of combined right and left side were used. Patients' relevant clinical and demographic data were collected. Modified Rodnan skin score (mRSS), hand mobility (HAMIS) and SSc Severity Scale (SScSS) were also assessed. Statistical analysis included Chi-Square test, Mann-Whitney U-test, Kruskal-Wallis and Spearman correlation coefficient. P value $<0.05$ was defined as statistically significant.

Results: A total of $186 \mathrm{MN}$ were assessed by US. Both groups had the same proportion of diabetes and history of tunnel carpal surgery $(p=0.803$ and $p=0.339$, respectively). Median of MNA and MNP were significantly higher in SSc patients ( $7.5 \mathrm{~mm}^{2}$ [6.6 to 9.5 ] and $13.8 \mathrm{~mm}$ [12.4 to 15], respectively) (median [interquartile range]) compared with controls $\left(7.0 \mathrm{~mm}^{2}\right.$ [6 to 8 ] and $12.9 \mathrm{~mm}$ [11.7 to 14], respectively) ( $p=0.021$ and $p=0.018$, respectively). Higher mRSS correlated with higher MNA (Spearman's rho $=0.335, \mathrm{p}=0.02$ ) and MNP ( $\mathrm{rho}=0.336, \mathrm{p}=0.02$ ). Values of MNA and MNP did not correlate with age, disease duration, HAMIS and SScSS, and were similar according to categories of gender and subset of disease $(p>0.05)$. However, median of MNA and MNP were significantly different between the 3 phases of skin involvement $(p=0.007$ and $p=0.009$, respectively), being higher in patients in the oedematous phase (median MNA of $9.25 \mathrm{~mm}^{2}[7.5$ to 11.5 ] and median MNP of $14.5 \mathrm{~mm}$ [13.5 to 16.9]).

Conclusions: Our study confirmed an increased MNA and MNP in SSc patients in comparison with healthy age and sex matched controls. Patients in the oedematous phase of skin involvement and patients with higher skin thickness assessed by mRSS showed higher MNA and MNP values.

References:

[1] Bandinelli $F$ et al. Early detection of median nerve syndrome at the carpal tunnel with high-resolution $18 \mathrm{MHz}$ ultrasonography in systemic sclerosis patients. Clin Exp Rheumatol. 2010; 28:15-8.

Disclosure of Interest: None declared

DOI: 10.1136/annrheumdis-2017-eular.4535

\section{FRI0653 SALIVARY GLAND ULTRASOUND IS RELATED TO AUTOIMMUNITY IN PRIMARY SJÖGREN SYNDROME}

J.C. Nieto-González ${ }^{1}$, F.J. López-Longo ${ }^{1}$, E. Estrada ${ }^{2}$, E. Naredo ${ }^{3}$.

${ }^{1}$ Rheumatology, Hospital G.U. Gregorio Marañón; ${ }^{2}$ Psychology, Universidad Camilo José Cela; ${ }^{3}$ Rheumatology, Hospital Universitario Fundación Jiménez Díaz, Madrid, Spain

Background: Primary Sjögren syndrome (pSS) is a systemic autoimmune disease involving exocrine glands, mainly ocular and salivary glands. Salivary gland ultrasound (SGU), of submandibular and parotid glands, in pSS is characterized by hypo/anechoic rounded areas within gland parenchyma, losing the normal homogeneity of the glands (typical SGU) ${ }^{1}$. SGU is a reliable imaging technique for assessing gland echostructure in $\mathrm{pSS}^{2}$.

Objectives: The aim of our study is to evaluate the relation between typical SGU and clinical and laboratory data in pSS

Methods: We performed SGU to 100 patients with pSS from our rheumatology department selected randomly from a database. We used a semiquantitative score from 0 to 3 . Grades 0 and 1 were considered as normal and grades 2 and 3 were considered as typical for pSS. We retrospectively collected demographics (age, gender, disease duration), clinical (extra-glandular manifestations, parotid swelling and lymphoma) and laboratory data (ESR, CRP, rheumatoid factor (RF), antinuclear antibodies (AAN), anti-SSA and anti-SSB antibodies). We divided the patients into 3 groups depending on their autoimmunity profile. Complete seropositive group were patients with RF, AAN and antiSSA or antiSSB positives simultaneously or sequentially. Simple seropositive group were patients with any positive autoantibody (RF/AAN/antiSSA or antiSSB) but not all of them together. Finally, patients without positive autoantibodies were included in the seronegative group

Results: We excluded 7 patients because they were diagnosed with secondary SS. From 93 pSS patients analyzed, 32 (frequency $34.5 \%$ ) had a typical SGU. Demographics, extra-glandular manifestations and lymphomas were similar between patients with typical SGU and patients with normal SGU. Parotid swelling and longer disease duration were associated with a typical SGU $(p<0.05)$. Patients with positive autoantibodies (AAN, RF, antiSSA and antiSSB) had more frequently a typical SGU. Complete seropositive group had the highest frequency of typical SGU, followed by simple seropositive group. All seronegative patients had a normal SGU. SGU relation with autoimmunity is shown in table 1

Conclusions: Longer disease duration and parotid swelling were associated with typical SGU. Typical SGU was associated with positive autoimmunity, moreover all seronegative patients had a normal SGU

\section{References:}

[1] Bialek EJ. US of the major salivary glands: anatomy and spatial relationships, pathologic conditions, and pitfalls. Radiographics 2006.

\begin{tabular}{lcccc}
\hline & Total & Typical SGU & Normal SGU & $p$ \\
\hline$n(\%)$ & $n=93$ & $n=32$ & $n=61$ & \\
Complete seropositive group & $36(38.7)$ & $25(78.1)$ & $11(18.0)$ & $<0.001$ \\
Simple seropositive group & $44(47.3)$ & $7(21.9)$ & $37(60.7)$ & $<0.001$ \\
Seronegative group & $13(14)$ & 0 & $13(21.3)$ & $<0.001$ \\
AAN $+(\mathrm{n}: 90)$ & $70(76.9)$ & $31(96.9)$ & $39(66.1)$ & $\mathbf{0 . 0 0 1}$ \\
$\mathrm{RF}+(\mathrm{n}: 92)$ & $55(59.1)$ & $28(87.5)$ & $27(44.3)$ & $<0.001$ \\
Anti-Ro $+(\mathrm{n}: 86)$ & $46(52.9)$ & $27(84.4)$ & $19(34.5)$ & $<0.001$ \\
Anti-La + $(\mathrm{n}: 86)$ & $28(33.3)$ & $19(63.3)$ & $9(16.7)$ & $<\mathbf{0 . 0 0 1}$ \\
\hline
\end{tabular}

[2] Damjanov N, Milic V, Nieto-González JC, et al. Multiobserver Reliability of Ultrasound Assessment of Salivary Glands in Patients with Established Primary Sjögren Syndrome. J Rheumatol. 2016.

Disclosure of Interest: None declared

DOI: 10.1136/annrheumdis-2017-eular.3571

\section{FRI0654 ULTRASOUND DETECTED PATHOLOGY IN THE ENTHESIS OF THE LOWER LIMB IN AN AGE STRATIFIED COHORT OF ASYMPTOMATIC SUBJECTS -A PROSPECTIVELY DESIGNED DESCRIPTIVE CROSS-SECTIONAL STUDY}

J. Guldberg-Møller ${ }^{1}$, S.M. Nielsen ${ }^{1}$, M.J. Koenig ${ }^{2}$, S. Torp-Pedersen ${ }^{3}$, L. Terslev ${ }^{4}$, A. Torp-Pedersen ${ }^{1}$, R. Christensen ${ }^{1}$, H. Bliddal ${ }^{1}$, K. Ellegaard ${ }^{1}$

${ }^{1}$ The Parker Institute, Frederiksberg; ${ }^{2}$ Department of radiology, Herlevand Gentofte Hospital, Gentofte; ${ }^{3}$ Department of radiology, Righhospitalet;

${ }^{4}$ Rigshospitalet, Glostrup, Denmark

Background: Ultrasound (US) examination of the entheses is increasingly used to document pathological changes in e.g. psoriasis arthritis and spondyloarthritis. Grey-scale (GS) US is used to assess morphological changes and Doppler US to assess increased blood flow.

The OMERACT expert group has agreed on the following elementary components when assessing the entheses on US examination; hypoechogenicity, increased thickness, enthesophytes/ calcifications, erosions, and Doppler activity (1).

Little is known about US assessment of the entheses in asymptomatic persons, thus the frequency and distribution of the above components between genders and age groups is uncertain.

Objectives: To investigate the frequency of enthesitis components in the entheses of the lower limb in a group of healthy subjects.

Methods: We recruited 64 subjects (32 women and 32 men), eight women and eight men in four decades, from 20 to 59 years. None of the subjects had previous or present signs of tendon or joint disease in the lower extremities. None of the participants took any kind of medication.

All subjects were examined by a rheumatologist and blood samples were collected to rule out any clinical signs of tendon or joint disease e.g. swollen and tender

\begin{tabular}{|c|c|c|c|c|c|c|c|c|c|}
\hline \multirow{3}{*}{$\begin{array}{c}\text { Quadriceps tendon } \\
\text { Doppler activity }\end{array}$} & \multirow{2}{*}{\multicolumn{2}{|c|}{$\begin{array}{l}\text { Age } \\
(\mathrm{n}=8 / 8) \\
\mathrm{F} \quad \mathrm{M}\end{array}$}} & \multirow{2}{*}{\multicolumn{2}{|c|}{$\begin{array}{l}\text { Age } 30-39 \\
(n=8 / 8) \\
F \quad M\end{array}$}} & \multicolumn{2}{|c|}{$\begin{array}{l}\text { Age } 40-49 \\
(\mathrm{n}=8 / 8)\end{array}$} & \multicolumn{2}{|c|}{$\begin{array}{l}\text { Age } 50-59 \\
(\mathrm{n}=8 / 8)\end{array}$} & \multirow{3}{*}{$\begin{array}{l}\begin{array}{l}\text { Total } \\
(\mathrm{n}=64)\end{array} \\
3(5 \%)\end{array}$} \\
\hline & & & & & $\mathrm{F}$ & $\mathrm{M}$ & F & M & \\
\hline & & 1 & & & & 1 & & 1 & \\
\hline \multirow{2}{*}{$\begin{array}{r}\text { Enthesophyte/calcifications } \\
\text { Increased thickness }\end{array}$} & 1 & 4 & 3 & 2 & 1 & 4 & 2 & 5 & $22(34 \%)$ \\
\hline & & 1 & & & & 1 & & & $2(3 \%)$ \\
\hline Hypoechogenicity & & 1 & & & & 1 & & 1 & $3(5 \%)$ \\
\hline $\begin{array}{l}\text { Patella tendon proximal } \\
\text { Doppler activity }\end{array}$ & & & & & & & & & 0 \\
\hline Enthesophyte/calcifications & 1 & & & & & & & 1 & $2(3 \%)$ \\
\hline \multirow[t]{2}{*}{ Increased thickness } & & & 1 & & & & 1 & 1 & $3(5 \%)$ \\
\hline & & & 1 & & & & 1 & 1 & $3(5 \%)$ \\
\hline \multirow{2}{*}{$\begin{array}{l}\text { Patella tendon distal } \\
\text { Doppler activity } \\
\text { Enthesophyte/ calcifications }\end{array}$} & & & & & & & & 1 & $1(2 \%)$ \\
\hline & & & 1 & & & & 1 & 1 & $3(5 \%)$ \\
\hline \multirow[t]{2}{*}{ Increased thickness } & & & 2 & & 1 & 2 & 1 & 3 & $9(14 \%)$ \\
\hline & & & 1 & & 1 & 1 & 1 & 2 & $6(9 \%)$ \\
\hline \multirow{2}{*}{$\begin{array}{l}\text { Achilles tendon } \\
\quad \text { Doppler activity } \\
\text { Enthesophyte/ calcifications }\end{array}$} & & & & & & & & & 0 \\
\hline & 3 & 3 & 1 & 6 & 2 & 5 & 2 & 4 & $26(41 \%)$ \\
\hline \multirow[t]{2}{*}{ Increased thickness } & & 1 & & 3 & & 1 & & 1 & $6(9 \%)$ \\
\hline & & & & & & & & & 0 \\
\hline $\begin{array}{l}\text { Plantar fascia } \\
\text { Enthesophyte/ calcifications }\end{array}$ & & & & & & & 1 & & $1(2 \%)$ \\
\hline \multirow{2}{*}{$\begin{array}{l}\text { Increased thickness } \\
\text { Hypoechogenicity }\end{array}$} & 1 & 1 & & 2 & 1 & 2 & 1 & & $8(13 \%)$ \\
\hline & 1 & & & 1 & & 1 & & & $3(5 \%)$ \\
\hline
\end{tabular}

F, female: M, male. All empty fields have the value 0 . 